\title{
Foraging zones of royal penguins during the breeding season, and their association with oceanographic features
}

\author{
Cindy L. Hull ${ }^{1, *}$, Mark A. Hindell ${ }^{1}$, Kelvin Michael ${ }^{2}$ \\ 'Zoology Department, University of Tasmania, GPO Box 252C, Hobart, Tasmania 7001, Australia \\ ${ }^{2}$ Antarctic CRC and Institute of Southern Ocean and Antarctic Studies, University of Tasmania, GPO Box 252-77, Hobart, \\ Tasmania 7001, Australia
}

\begin{abstract}
Satellite transmitters were deployed on breeding royal penguins at Macquarie Island during 4 stages (first male foraging trip during incubation, $\mathrm{n}=2$; first female foraging trip during incubation, $\mathrm{n}=3$; guard, $\mathrm{n}=4$; and early creche, $\mathrm{n}=1$ ) of the $1994 / 5$ and $1995 / 6$ breeding seasons. From these data, foraging zones, oceanographic features of the zones, and travelling behaviours were determined. Foraging trip length, area of foraging zone, and distance travelled were strongly correlated, and were greatest during incubation. The estimated rate of travel (mean velocity) was constant across indivjduals and stages in the breeding season. No diurnal patterns in rates of travel were detected, nor any patterns on different days of a foraging trip. A meander coefficient (the degree of linear travel, to give an indication of foraging activity) was constant between stages in the breeding season, and day of the foraging trip, but was greater from 07:00 to 18:00 h, suggesting increased foraging activity. Foraging during all stages of the breeding season was offshore, in deep water (greater than $2000 \mathrm{~m}$ ) and in the polar frontal zone. During the incubation stage the foraging zones were circular, with a low Foraging Zone Coefficient (FZC: maximum distance from the colony divided by area of the foraging zone), but more direct with a higher FZC after chicks hatched. These different patterns are thought to be associated with prey resources in the region. It is concluded that the foraging behaviour of royal penguins is closely linked to the polar frontal zone, their prey, and the constraints of the breeding season.
\end{abstract}

KEY WORDS: Royal penguin · Foraging $\cdot$ Satellite tracking $\cdot$ Polar frontal zone

\section{INTRODUCTION}

Penguins are important consumers of marine resources (Croxall \& Lishman 1987), but for most species little is known about how they interact with the biotic and abiotic components of the marine system. It is postulated that the foraging zones of penguins, like other seabirds, are influenced by: (1) oceanographic processes acting at several spatial scales (Hunt \&

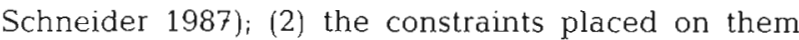
during the breeding season, such as relieving incubating partners and feeding chicks (Wilson et al. 1995); and (3) prey distribution (Hunt 1990)

·E-mail:cl_hull@postoffice.utas.edu.au
The limited data on penguins at sea suggest that they are not randomly distributed (Veit et al. 1993), but patchy, like many other species of seabird (Hunt 1988). Patchiness in seabird distribution can often be related to aspects of the physical (and biological) environment. For example, correlations have been demonstrated between seabird distribution and oceanic fronts (Ainley \& Jacobs 1981, Abrams 1985, Schneider 1990), and eddies (Haney \& McGillivary 1985, Abrams \& Miller 1986, Haney 1986). Distribution can be described at a variety of temporal and spatial scales: mega scales (greater than $3000 \mathrm{~km}$ ) relate to biogeographical regions; macro scales (1000 to $3000 \mathrm{~km}$ ) to regions of higher or lower productivity within them; meso scales $(100$ to $1000 \mathrm{~km})$ to the interactions between larger scale features; coarse scales to the borders of these fea- 
tures with each other and with land or ice; and fine scales to interactions with prey (Hunt \& Schneider 1987). The advent of telemetric and/or data logging devices has now allowed the examination of these relationships in species of penguin (eg. Ancel et al. 1992, Jouventin et al. 1994, Wilson et al. 1995, Davis et al. 1996, Bost et al. 1997).

Royal penguins Eudyptes schlegeli are the only endemic species of penguin on Macquarie Island, there being an estimated 850000 breeding pairs (Copson \& Rounsevell 1987). Whilst some aspects of their biology have been investigated, such as breeding (eg. Warham 1971, Carrick 1972) and diet (Horne 1985, Hindell 1988), details of their foraging ecology are unknown. Estimates of foraging ranges have been made from foraging trip durations and assumed swimming speeds (Horne 1985, Croxall \& Lishman 1987), and extrapolations from the closely related macaroni penguin E. chysoiophus (Scott 1994). Some records of royal penguins at sea have also been obtained during voyages (Woehler et al. 1990, Reid et al. in press), but the age and breeding status of these individuals is generally unknown.

The purpose of the current study was to assess the meso-scale interaction between royal penguins and the oceanographic environment. Foraging zones were investigated throughout the breeding season and compared to oceanographic and productivity features of the local environment. Where possible any travelling behaviours were characterised.

\section{MATERIALS AND METHODS}

Deployments. Royal penguins from Sandy Bay (upper colony) on the east coast of Macquarie Island $\left(54^{\circ} 33^{\prime} 51^{\prime \prime} \mathrm{S}, 158^{\circ} 54^{\prime} 11^{\prime \prime} \mathrm{E}\right)$ were used in this study. Known breeding birds were selected, sexed by measurements of bill length and depth (Hull in press a) and marked with a coloured velcro flipper band, which was removed when the birds returned to the colony (banding of penguins allowed the confirmation of the return of a bird when a satellite transmitter was lost). Telonics ST-10 satellite transmitters (932 E Impala Ave, Mesa, AZ, USA) were attached to the lower medial part of each penguin's back (to minimise drag; Bannasch et al. 1994) using a cyanoacrylate adhesive (Loctite 401), with cable ties passed through the birds' feathers and locked around the device. The transmitters were affixed to the birds at the nest site using the techniques described by Hull \& Wilson (1996).

The satellite transmitters had saltwater switches (to transmit only when the penguins were on the surface, thereby saving power), were embedded in resin (for protection against high pressure when the penguins were diving), and then potted in black, waterproof housings (Sirtrack, Private Bag 1404, Havelock North, New Zealand). Four such transmitters were deployed during the $1994 / 5$ and $1995 / 6$ breeding seasons. The devices were $95 \times 42 \times 20 \mathrm{~mm}$ (representing approximately $4 \%$ of the frontal cross-sectional area of royal penguins), weighed $80 \mathrm{~g}$ and were streamlined to reduce drag (eg. Wilson et al. 1986). A total of 10 deployments was made as follows (number of deployments is shown in parentheses): first male trip during incubation (2); first female trip during incubation (3); guard stage (2 females undertaking 2 trips each, only females forage at this time); and creche stage (1 male).

Preliminary analysis/filtering. Data were extracted, edited and validated from the dispose and diagnostic files using SATPAK software (Wildlife Computers, 16150 NE 85th St, Redmond, WA, USA). The accuracy of each location class was estimated from the error at a known position on land (using a Global Positioning System receiver, with an accuracy of $70 \mathrm{~m}$ or better). All locations were filtered to remove aberrant data using the technique described by McConnell et al. (1992) and assuming a maximum swimming speed of $10 \mathrm{~km} \mathrm{~h}^{-1}$, calculated from the most reliable location classes (1,2 and 3) and from published swimming speeds for macaroni penguins (Clarke \& Bemis 1979, Brown 1987, Wilson et al. 1989).

Rates of travel, comprising all activities from resting to porpoising and diving, between consecutive locations for the filtered data were calculated and log-transformed (due to lack of normality). These data were compared across stages of the breeding season using a nested ANOVA (individuals nested in stages), and across days of the foraging trip by categorising days into 3 groups: (1) Days 1 and 2 (outgoing leg); (2) middle of the trip; (3) last 2 days (return leg), and analysing with a repeated measures ANOVA. Similarly, rates of travel during different hours of the day were compared by categorising the day into four $6 \mathrm{~h}$ blocks: (1) 00:00-06:00; (2) 07:00-12:00; (3) 13:00-18:00; (4) 19:00-24:00 h and analysing with a repeated measures ANOVA.

A Foraging Zone Coefficient (FZC) was calculated as the maximum distance travelled $(\mathrm{km})$ divided by the area of the foraging zone $\left(\mathrm{km}^{2}\right)$ (derived from home range analysis, see below). A meander coefficient, representing the degree of non-linear swimming, was calculated by determining the deviation of points from the $45^{\circ}$ regression line of speed $\times$ distance on filtered locations. This was carried out on locations between 1 and 2 h apart. Coarser temporal resolutions could not be used due to the inaccurate representation of rates of travel (see 'Results'). Locations less than $1 \mathrm{~h}$ apart were not used because it was felt that the error margins inherent in the ARGOS estimation of location (see Table 1) would mask some of the meandering behav- 
iour over this limited time period. Although this meant that there was an underestimate of rates of travel compared to locations less than $1 \mathrm{~h}$ apart, it was felt this temporal resolution was the most suitable way to describe meandering behaviour. Data were log-transformed, due to lack of normality, and analysis was carried out in the same manner as for rates of travel, using a nested ANOVA to compare stages in the breeding season, and repeated measures ANOVAs to compare day of the foraging trip and time of the day.

Foraging zones. Home range analysis was used to assess clusters of locations (CL), the area of foraging zones, as well as the degree of overlap between zones. As the probability of a penguin being at any position in the zone (the utilisation distribution) was not of interest, the temporal spacing of locations and issues of autocorrelation did not apply (White \& Garrott 1990). Locations were converted to cartesian co-ordinates using CALHOME (CALifornia HOME Range, US Forest Service, Pacific SW Research Station, CA, USA), and home range analysis was performed using a fixed Kernel Analysis from Ranges V (Kenward \& Hodder, Institute of Terrestrial Ecology, Dorset, UK), incorporating an objective smoothing factor and $85 \%$ isopleths, to describe the foraging zones. CL were used as an indication of presumed increased foraging activity. As reduced rates of travel in king Aptenodytes patagonicus and emperor A. forsteri penguins coincide with a higher local density of satellite locations, and are positively associated with feeding bouts (Ancel et al. 1992, Bost et al. 1997), CL were considered an appropriate indicator. CL were determined using $40 \%$ isopleths (from home range analysis), as these described core areas in the zone. Core areas were defined using the technique of Wray et al. (1992). This involves calculating the area of a range from successive isopleths, and using the isopleth which results in the greatest increase in area.

Incremental analysis was used to determine the number of locations required to accurately represent a foraging zone (Ford \& Krumme 1979). This was performed by randomly selecting locations from a complete track; those from a representative female during incubation stage. It was not possible to undertake this analysis on all the other individuals, because they had either incomplete tracks, trips of short duration, or nonrepresentative data (the aberrant female, see below). The following numbers of locations were used: 10,20 , $30,40,50,60,70$ and 80 , with 10 replicates of each randomly selected. The area of the derived foraging zone was then plotted and the point of the areal asymptote indicated the minimum number of locations required (Ford \& Krumme 1979).

Oceanographic influence. There are scant data available on the oceanographic conditions around Macquarie Island (see Gordon 1972), and none on the prey resources. Therefore, assessments of the abiotic and biotic features of zones in which royal penguins foraged had to be evaluated using satellite data. Contemporaneous, weekly sea surface temperatures at a spatial scale of $19 \times 19 \mathrm{~km}$ (NASA PO.DAAC data) were used to describe oceanographic features. There were no contemporaneous data on productivity levels available, therefore an indicator of productivity was derived from phytoplankton pigment concentration composite data at a spatial resolution of $1 \times 1 \mathrm{~km}$, for the period 1978 to 1986 (NASA CZCS data). Bathometry data were obtained from the Australian Antarctic Division. Mean values \pm SD are used throughout.

\section{RESULTS}

\section{Satellite tracking data}

An average of 13 locations were received per $24 \mathrm{~h}$ period (pre-filtering) (Table 1), with marginally less locations received during the 1994/5 (average 13.0 \pm $3.5 \mathrm{~d}^{-1}$ ) than the $1995 / 6$ season (average $14.1 \pm 3.5 \mathrm{~d}^{-1}$ ).

Table 1. Percentage of locations received and calculated errors $(\mathrm{km})$, when penguins were at a known location on land, in each location class

\begin{tabular}{|ccccc|}
\hline Location class & $\begin{array}{c}\text { Locations received } \\
1994 / 5(\%)\end{array}$ & $\begin{array}{c}\text { Locations received } \\
1995 / 6(\%)\end{array}$ & $\begin{array}{c}\text { Latitudinal error: } \\
\text { average (range) }\end{array}$ & $\begin{array}{c}\text { Longitudinal error: } \\
\text { average (range) }\end{array}$ \\
\hline 3 & 0.5 & 1.0 & $1.0(0.5-1.5)$ & $0.6(0.1-1.1)$ \\
2 & 1.3 & 1.9 & $1.0(0.2-1.5)$ & $0.9(0.1-1.4)$ \\
1 & 6.6 & 20.0 & $1.0(0.1-1.7)$ & $1.0(0.0-4.1)$ \\
Total 1, 2,3 & 8.4 & 22.9 & & $8.7(0.1-100.8)$ \\
0 & 56.4 & 51.0 & $7.0(0.1-89.2)$ & $14.9(0.2-145.3)$ \\
A & 16.2 & 11.6 & $9.0(0.1-40.2)$ & $4.6(0.1-14.7)$ \\
Z & 11.6 & 14.4 & $4.0(0.3-6.1)$ & $44.2(1.2-112.8)$ \\
Total 0, A, B, Z & 7.4 & 0.1 & $29.0(6.6-63.7)$ & 95 \\
\hline
\end{tabular}



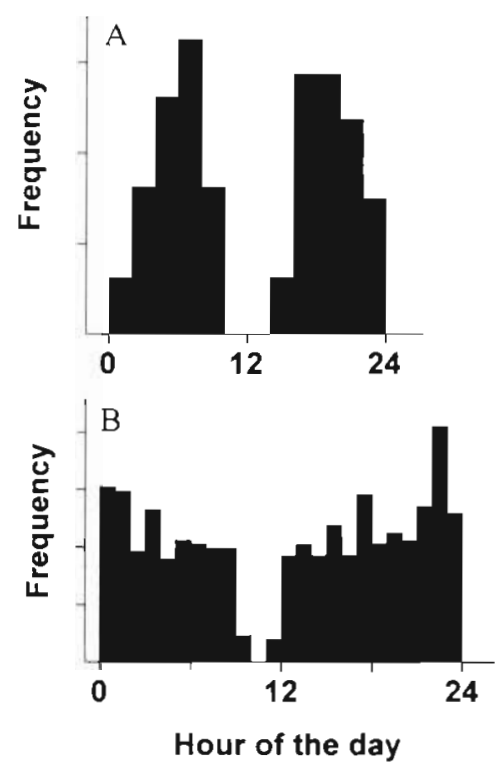

Fig. 1. Number of locations received over a 24 h period during each year of the study. (A) 1994/5, (B) 1995/6

There was a bimodal distribution in the number of locations received during a $24 \mathrm{~h}$ period, with none available around midday (local time) (Fig. 1). The absence of signals was longer $(4 \mathrm{~h})$ in the $1994 / 5$ season than the 1995/6 season ( $2 \mathrm{~h}$ ). The number of locations retained after filtering also varied between seasons. During the $1994 / 5$ season only $160(22.2 \%)$ were retained, whilst $757(54.8 \%)$ were retained during the 1995/6 season.

Successive locations were separated by between $3 \mathrm{~min}$ and $67 \mathrm{~h}$ (average $3.8 \mathrm{~h}$ ). Aside from the reduction in locations around midday, the frequency of locations varied with time of day $\left(F_{22.878}=2.585, \mathrm{p}<0.001\right)$, with 15:00 h (local time, GMT $+10 \mathrm{~h}$ ) having the most locations. Regressions of speed and distance calculated from locations $<1,1-2,2-3$, and $3-4 \mathrm{~h}$ apart were significantly different (ANCOVA, $F_{3,295}=1840.700, \mathrm{p}<$ 0.001) (Fig. 2). This indicated that rates of travel estimated from locations separated by different time periods were not constant, and that greater separations led to more severe underestimates of rates of travel. All further analyses refer to filtered data, and rates of travel are calculated from locations $<1 \mathrm{~h}$ apart.

\section{Travelling behaviour}

Rates of travel were constant across the breeding season $\left(F_{3,4}=0.72, p>0.05\right)$ (Table 2$)$, days of the foraging trip $\left(F_{6,6}=0.39, p>0.05\right)$, and time of day $\left(F_{2,10}=\right.$ $0.431, p>0.05$ )

The meander coefficients varied from 0.0 to -11.95 (mean $=-2.16 \pm 1.78)$, where 0.0 represented swim-
Table 2. Eudyptes schlegeli. Estimated rate of travel by royal penguins (mean $\pm \mathrm{SD}$ ). (Locations less than $1 \mathrm{~h}$ apart)

\begin{tabular}{|lcc|}
\hline Stage & $\begin{array}{c}\text { Mean rate of } \\
\text { travel }\left(\mathrm{km} \mathrm{h}^{-1}\right)\end{array}$ & $\begin{array}{c}\text { Number of } \\
\text { estimates }\end{array}$ \\
\hline Males during incubation & $6.1 \pm 5.4$ & 27 \\
Females during incubation & $7.8 \pm 4.5$ & 132 \\
Guard & $4.6 \pm 3.4$ & 13 \\
Creche & $5.0 \pm 3.8$ & 25 \\
Combined & $7.0 \pm 4.6$ & 197 \\
\hline
\end{tabular}

ming in a straight line and increased negative coefficients indicated a greater degree of meandering. There were no significant differences in the degree of meandering between stage in the breeding season $\left(F_{1,2}=1.78, p>0.05\right)$. Degree of meandering was constant across day of the foraging trip $\left(F_{2,12}=1.34, p>\right.$ 0.05 ), but varied significantly with hour of the day $\left(F_{3,18}=6.692, \mathrm{p}<0.007\right)$. The greatest degree of meandering occurred between $07: 00$ and 18:00 h.

\section{Home range analysis}

The number of locations per individual, after filtering, and used to define foraging areas ranged from 24 to 378 . The incremental analysis determined that a minimum of 20 locations were required to represent the foraging range of royal penguins during the breeding season.

The area of foraging zones and the FZC are given only for complete tracks. Of the 10 foraging zones obtained, 4 were incomplete because: (1) a device was lost from a male during incubation, therefore the return leg of the foraging trip was not complete (the bird did return to the colony, however); (2) a female during incubation did not return from her foraging trip; (3) another female during incubation remained absent from the colony for 2 mo, becoming a failed breeder and whose behaviour was subsequently regarded as aberrant; and (4) the antenna on a device deployed on the male during creche stage was damaged and did not transmit signals in the last stage of the foraging trip.

All foraging activity occurred offshore, to the southeast of Macquarie Island and south of the Campbell Plateau in the Emerald Basin (Figs. 3 to 6). The water in this region is 4000 to $5000 \mathrm{~m}$ deep. A maximum distance of over $600 \mathrm{~km}$ and minimum distance of $68 \mathrm{~km}$ was travelled from the colony, with the distance covered varying with stage in the breeding season (Table 3). There was a significant relationship between the duration of the foraging trip and the maximum distance travelled $\left(\mathrm{r}^{2}=0.475, F_{1}=6.336, \mathrm{p}<0.04\right)$. The relationship between duration of the foraging trip and 

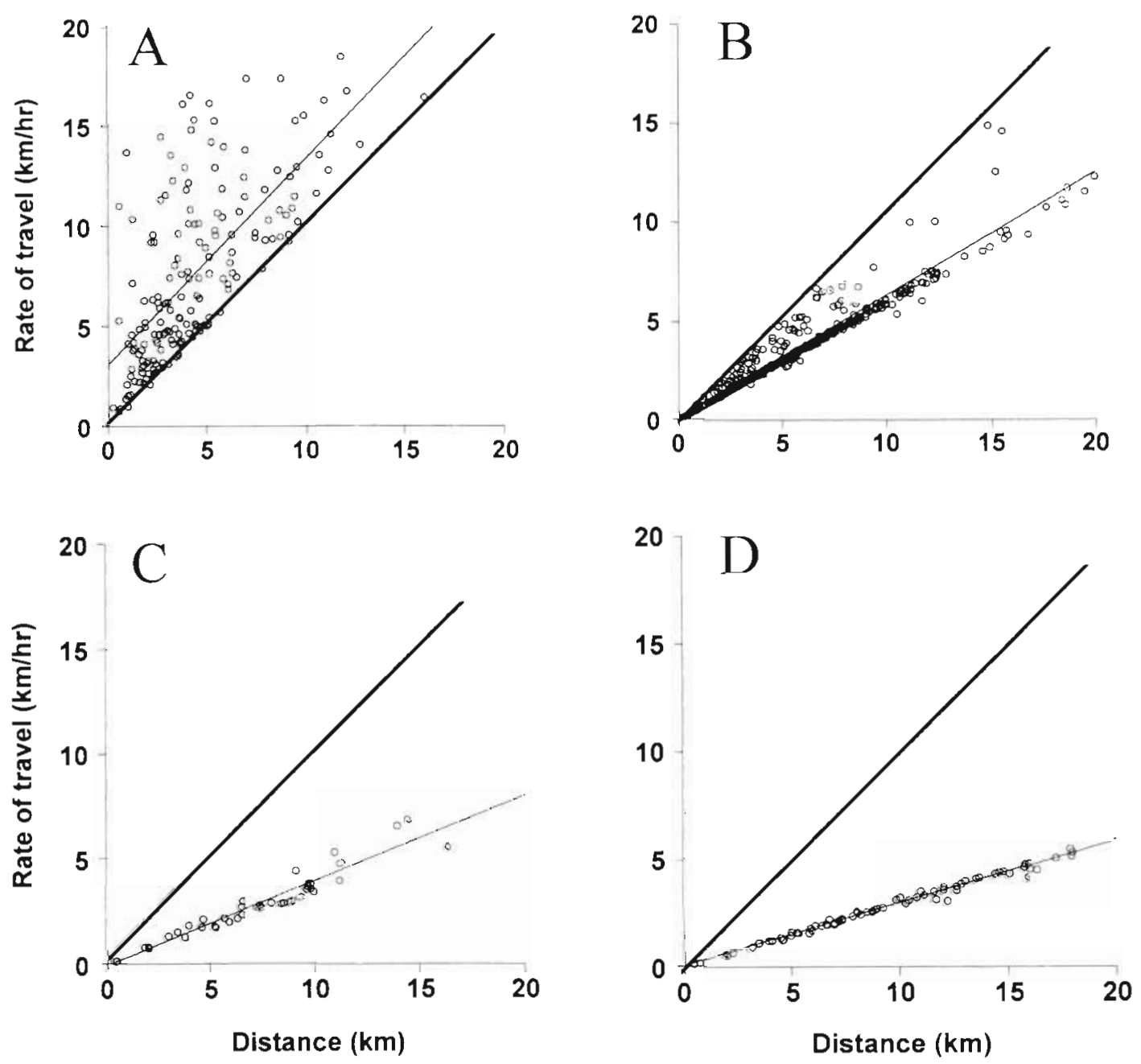

Fig. 2. Eudyptes schlegeli. Regressions of rate of travel and distance between consecutive locations of different temporal resolutions. (A) $<1 \mathrm{~h},(\mathrm{~B}) 1-2 \mathrm{~h},(\mathrm{C}) 2-3 \mathrm{~h}$, (D) $3-4 \mathrm{~h}$

area of the foraging zone was even stronger $\left(\mathrm{r}^{2}=0.805\right.$, $\left.F_{1}=20.670, \mathrm{p}<0.006\right)$.

All penguins left Macquarie Island and travelled due east before heading southeast, returning to the island in a clockwise path. The FZC increased as the season progressed (Table 4). During the incubation stage both male and female birds undertook 'circular' tracks (as defined by Jouventin et al. 1994) with large areas being covered. However, during the chick provisioning stage (guard and creche) the tracks were 'direct' (as defined by Jouventin et al. 1994) to specific areas of the foraging zones.

The degree of overlap of foraging zones for stages was low (average $22.4 \%$ ) (Table 5), indicating discrete foraging zones across the breeding season. Of the 90 comparisons only 11 had a degree of overlap greater than $50 \%$. These overlaps were between the incomplete male trip during incubation and most other trips, the aberrant female and guard stage trips, and within
Table 3. Eudyptes schlegeli. Maximum distance travelled, average distance per day and duration of foragnng trips by royal penguins during each stage of the breeding season

\begin{tabular}{|c|c|c|c|}
\hline Individual and stage & $\begin{array}{c}\text { Maximum } \\
\text { distance } \\
(\mathrm{km})\end{array}$ & $\begin{array}{c}\text { Average } \\
\text { distance } \\
\text { per day } \\
\text { (km) }\end{array}$ & $\begin{array}{l}\text { Duration } \\
\text { of trip } \\
\text { (d) }\end{array}$ \\
\hline 1. Male during incubation & 654.9 & 28.5 & 23 \\
\hline 2. Male during incubation & 664.2 & $31.6^{\prime}$ & 21 \\
\hline 3. Female during incubation & 269.2 & $-{ }^{a}$ & $--^{a}$ \\
\hline 4. Female during incubation & 415.7 & 29.7 & 14 \\
\hline 5. Female during incubation ${ }^{b}$ & b 587.7 & 18.4 & 68 \\
\hline 6. Guard (female) & 68.6 & 23.0 & 3 \\
\hline second trip & 131.0 & 43.7 & 3 \\
\hline 7. Guard (female) & 109.1 & 36.3 & 3 \\
\hline second trip & 153.5 & 51.2 & 3 \\
\hline 8. Creche (male) & 330.4 & $47.1^{\circ}$ & 7 \\
\hline
\end{tabular}



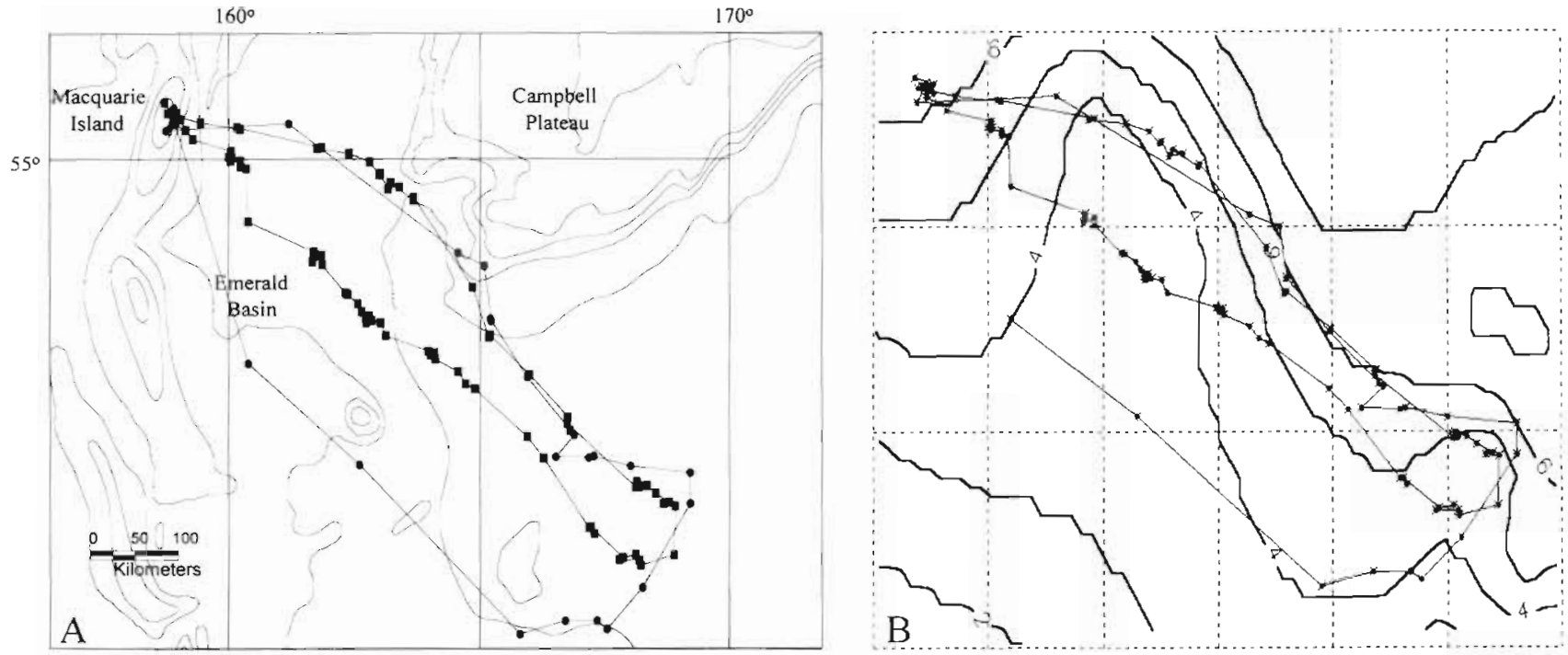

Fig. 3. Eudyptes schlegeli. Tracks of male royal penquins during the incubation stage: (•) male i. (incompieie ilack), (E) male 2 , showing (A) $1000 \mathrm{~m}$ bathometry lines and (B) contemporaneous sea surface temperatures $\left({ }^{\circ} \mathrm{C}\right)$ (NASA PO.DAAC data)
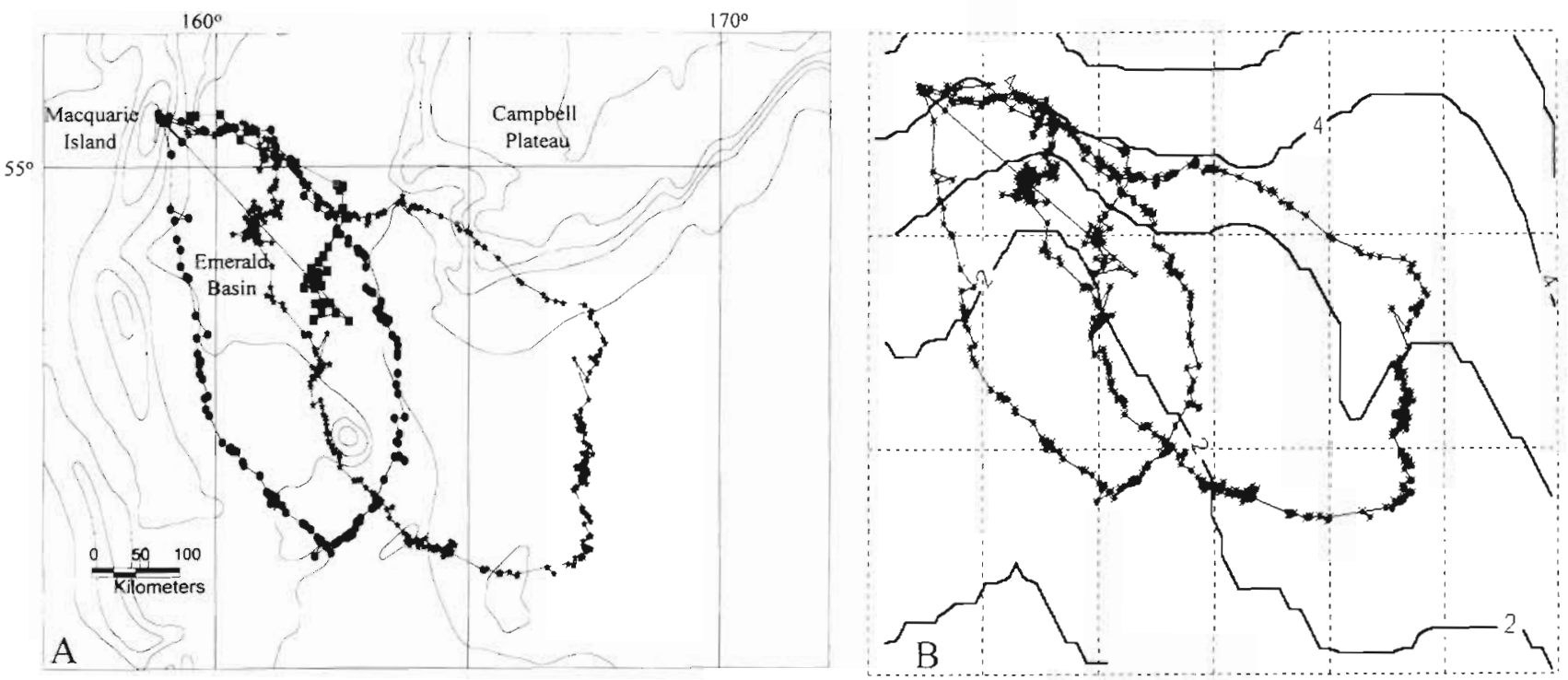

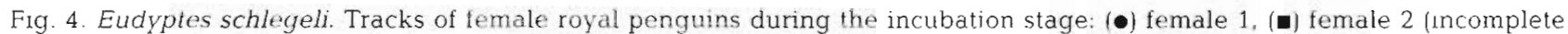
track), ( $\star$ ) female 3 (aberrant), showing (A) $1000 \mathrm{~m}$ bathometry lines and (B) contemporaneous sea surface temperatures $\left({ }^{\circ} \mathrm{C}\right.$ ) (NASA PO.DAAC data)

guard stage (Table 5). The results of the incomplete track of the male during incubation and the aberrant female must be viewed with caution as neither of these tracks may be representative.

\section{Oceanographic influence}

Sea surface temperature data indicated that all foraging took place in the Polar Frontal Zone (PFZ) (Figs. 3 to 6 ), in water that ranged between 2 and $6^{\circ} \mathrm{C}$.
The reliance on this zone was consistent throughout the breeding season, although the locations of females during incubation were in slightly cooler water. The PFZ moved further south during the summer, and there were no incications of any features such as eddies or gyres in this region at this time (NASA PO.DAAC data; Figs. 3 to 6 ).

Productivity levels, as signified by phytoplankton pigment concentrations, during both periods (October to December, incubation stage; January to March, chick provisioning) ranged from less than 80 to 160 

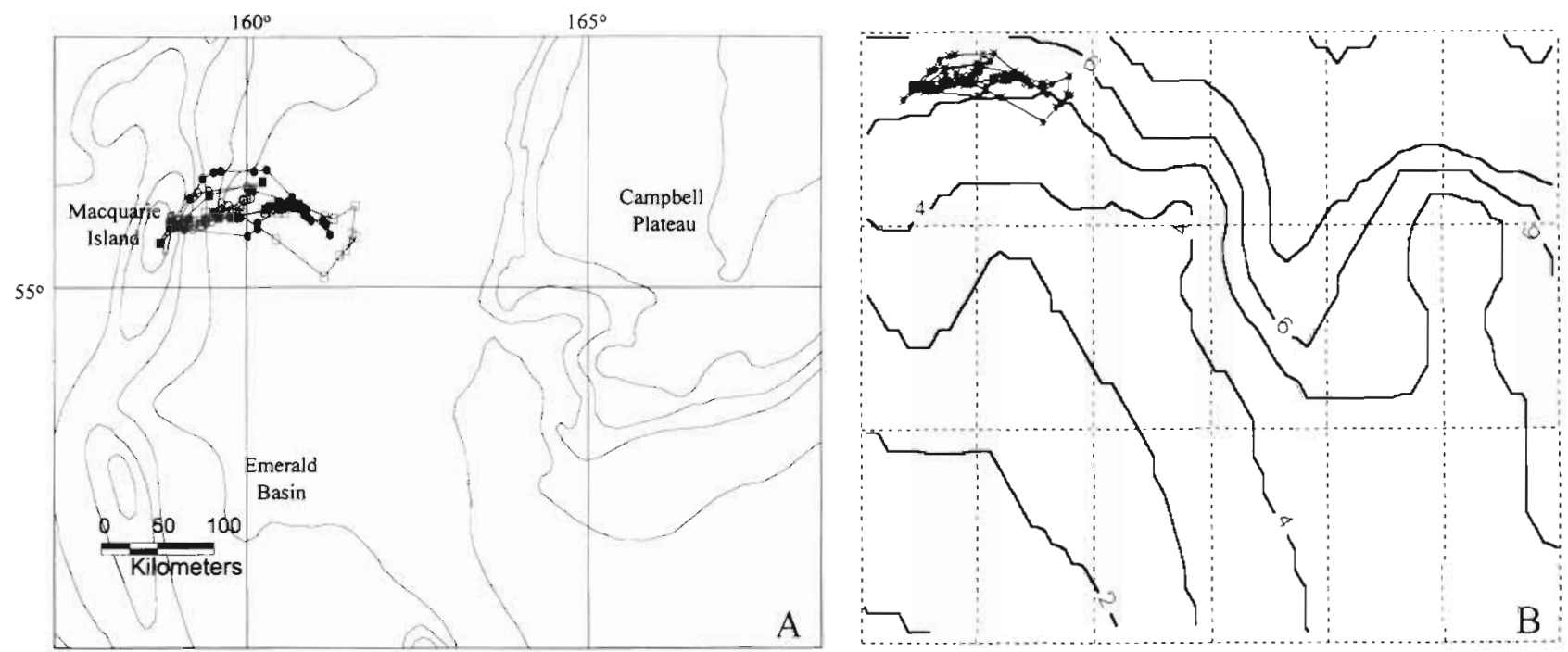

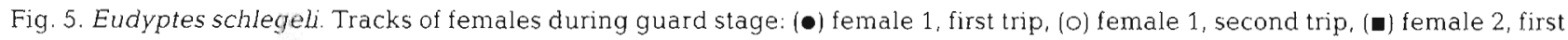
trip, (ם) female 2, second trip, showing (A) $1000 \mathrm{~m}$ bathometry lines and (B) contemporaneous sea surface temperatures $\left({ }^{\circ} \mathrm{C}\right.$ ) (NASA PO.DAAC data)
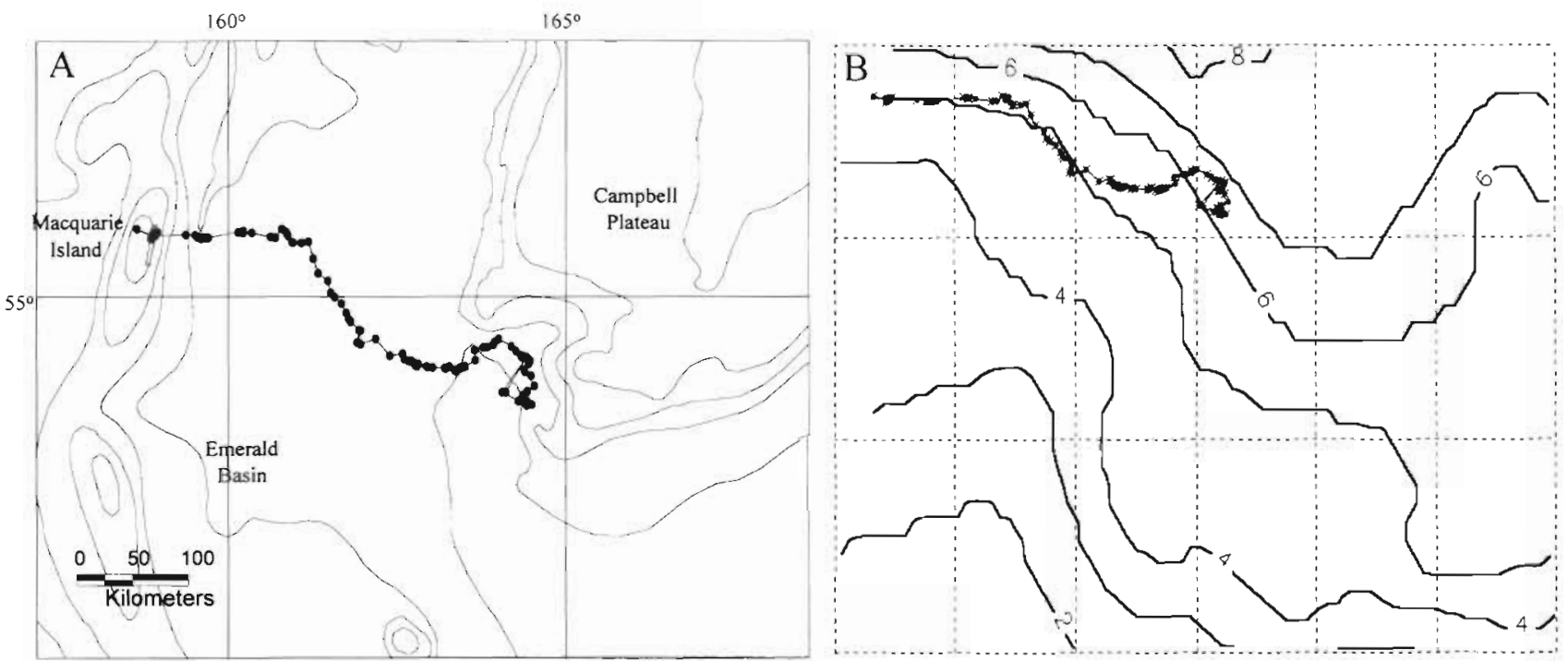

Fig. 6. Eudyptes schlegeli. Track of male during creche stage showing (A) $1000 \mathrm{~m}$ bathometry lines and (B) contemporaneous sea surface temperatures $\left({ }^{\circ} \mathrm{C}\right.$ ) (NASA PO.DAAC data)

Table 4. Eudyptes schlegeli. Centre of activity, area and Foraging Zone Coefficients (FZC) of royal penguin foraging zones (using $85 \%$ isopleths). Only complete trips are given. 'a' denotes second trip by the same individual

\begin{tabular}{|lccccr|}
\hline Stage & Deployment & Centre (distance from colony, km) & Area (ha) & FZC & Number of locations \\
\hline Male (incubation) & 1 & 626.3 & 1330 & 0.49 & 24 \\
Female (incubation) & 2 & 473.5 & 1720 & 0.24 & 151 \\
Guard & 3 & 162.6 & 2620 & 0.22 & 378 \\
& 1 & 65.0 & 200 & 0.34 & 29 \\
& $1 \mathrm{a}$ & 108.8 & 100 & 1.31 & 28 \\
& 2 & 92.9 & 50 & 2.18 & 31 \\
& $2 \mathrm{a}$ & 20.2 & 120 & 1.28 & 30 \\
\hline
\end{tabular}


Table 5. Eudyptes schlegeli. Degree of overlap (\%) between each royal penguin foraging trip derıved from home range analysis Trip: (1) male during incubation, (2) male during incubation, (3) female during incubation, (4) female during incubation, (5) female during incubation, (6) guard, (7) guard a, (8) guard, (9) guard a, (10) creche

\begin{tabular}{rrrrrrrrrrrr}
\hline Trip & 1 & 2 & 3 & 4 & 5 & 6 & 7 & 8 & 9 \\
\hline 1 & - & 34.6 & 0.6 & 4.0 & 26.8 & 1.1 & 1.3 & 1.6 & 4.0 & 2.7 \\
2 & 17.4 & - & 3.6 & 24.8 & 56.0 & 1.3 & 1.8 & 1.9 & 3.7 & 18.7 \\
3 & 6.7 & 100 & - & 30.9 & 90.4 & 6.8 & 0.0 & 3.4 & 9.4 & 30.5 \\
4 & 3.1 & 39.0 & 1.7 & - & 20.9 & 0.9 & 0.8 & 0.8 & 2.9 & 13.0 \\
5 & 12.6 & 53.1 & 3.1 & 12.5 & - & 0.0 & 1.0 & 0.7 & 1.2 & 12.9 \\
6 & 37.4 & 100 & 21.9 & 47.4 & 0.0 & - & 2.4 & 21.2 & 74.7 & 0.0 \\
7 & 33.6 & 93.9 & 0.0 & 28.6 & 57.9 & 1.9 & - & 45.8 & 47.3 & 8.9 \\
8 & 35.9 & 95.0 & 6.0 & 25.5 & 38.1 & 12.1 & 38.2 & - & 64.7 & 0.2 \\
9 & 48.0 & 92.2 & 4.5 & 7.9 & 45.1 & 30.4 & 20.3 & 19.3 & - & 4.5 \\
10 & 4.7 & 63.3 & 3.6 & 26.8 & 46.0 & 0.0 & 0.5 & 0.1 & 0.6 & - \\
\hline
\end{tabular}

counts: 1 count $=\left[\log _{10}(\right.$ pigment $\left.)+1.4\right] / 0.012(\mathrm{NASA}$ PO.DAAC). Productivity was variable in the region and whilist $C \dot{L}$ ố the penguirs uverlapped to some extent with regions of highest productivity it was not confined to these areas (Fig. 7).

\section{DISCUSSION}

\section{ARGOS data}

The NOAA satellites pass on average 16 times $\mathrm{d}^{-1}$ at the latitude of Macquarie Island (ARGOS manual), therefore in this study, locations were received during $81 \%$ of satellite passes. The difference in the number and quality of locations received between the 1994/5 and $1995 / 6$ seasons is due to the commissioning of the NOAA J satellite by ARGOS in early 1995, which resulted in a reduction in non-standard and skipped (low class) locations (ARGOS manual). For this reason, more locations were filtered due to their aberrant nature in the $1994 / 5$ season $(77.8 \%)$, compared to the $1995 / 6$ season $(45.2 \%)$.

The error margins of all location classes calculated in this study were greater than those cited by ARGOS, and other studies (McConnell et al. 1992, Jouventin et al. 1994, Stewart \& DeLong 1995). This is probably due to the characteristics of the transmitters (size, insulation, power output, antenna type and oscillator stability which is influenced by thermal conditions; Stewart et al. 1989) and/or the latitude at which the signals were transmitted
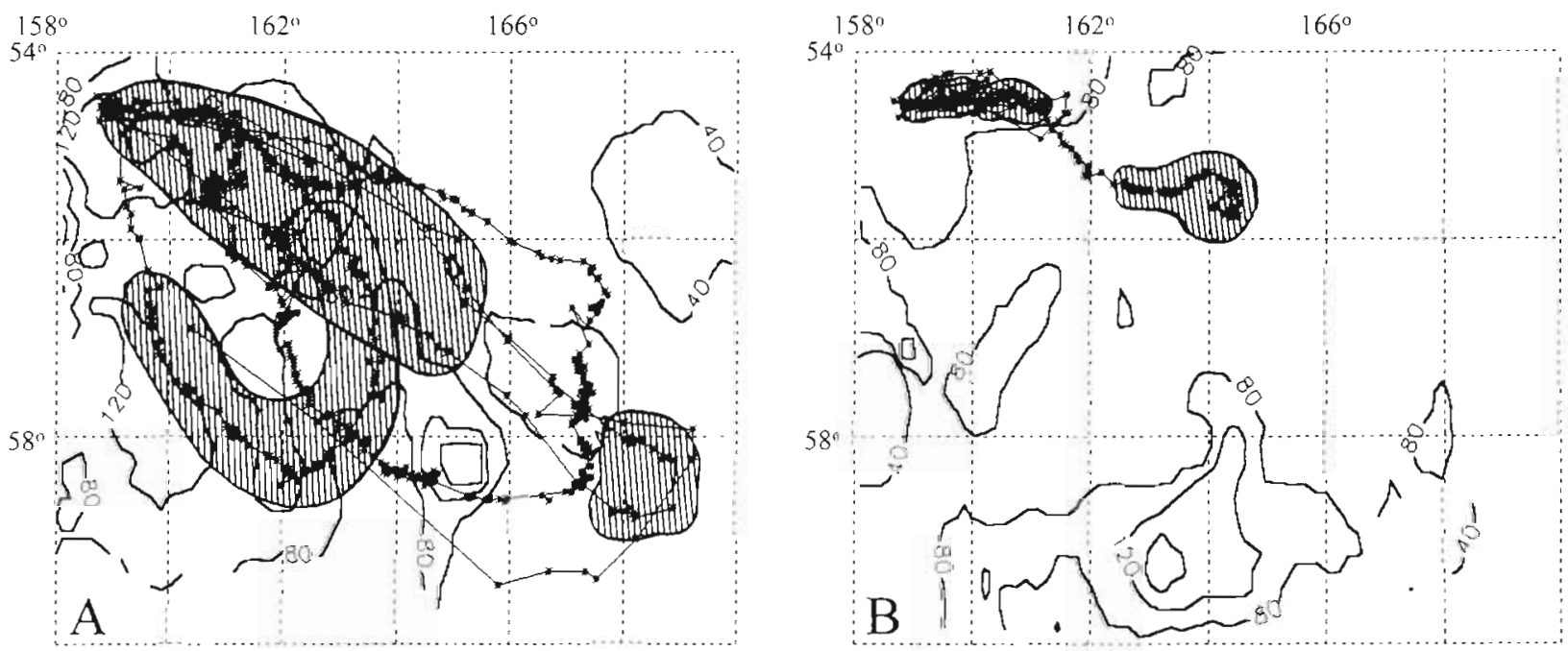

Fig. 7 Eudyptes schlegeli. Penguin tracks with $40 \%$ isopleths (hatched) showing clusters of locations overlaying productivity indicator. Productivity indicator derived from phytoplankton pigment counts, which have a logarithmic relationship to pigment concentrations (NASA CZCZ 1978-86 composite data sets). (A) October-December average with incubation stage tracks, 
The temporal spacing of locations significantly affected estimates of rates of travel (Fig. 2), as has also been shown by Walker et al. (1995). This arises because travel between consecutive locations is assumed to be a straight line. The further locations are apart in time, the more incorrect this assumption is, because birds rarely travel in straight lines when searching for prey (Walker et al. 1995). Estimates of rates of travel are best derived from locations as closely spaced as possible.

\section{Eiffects of devices}

It is likely that the foraging behaviour of royal penguins is affected to some extent by the satellite transmitters, as effects have been recorded when similarsized time depth recorders were deployed on this species (Hull in press b). However, we hope to have minimised effects by streamlining the transmitters to reduce drag (Bannasch et al. 1994). The antenna may have limited some of the advantage gained by streamlining, as Weavers (1992) estimated that $70 \%$ of the induced drag was due to the antenna in VHF transmitters. Other models of satellite transmitters resulted in increased foraging trip durations and changes in diving effort when attached to king penguins (Bost et al. 1997), and increased foraging trip durations and reduced mass gain when attached to Adélie penguins Pygoscelis adeliae (Kerry et al. 1995). Aside from the aberrant female and the creche male, the foraging trip durations of all royal penguins in this study were the same as birds without transmitters (C. Hull unpubl. data). This suggests that the impact from the transmitters was probably only marginal, as foraging trip durations were one of the variables significantly affected by the addition of large, unstreamlined devices (Hull in press $b$ ). The foraging duration of the creche male was longer than the average, suggesting that this track may not be representative of birds in this stage. Aside from this trip, it is assumed that the foraging zones of royal penguins were not significantly affected by the attachment of these devices (cf. Bost et al. 1997), although this does not discount the possibility that other aspects of royal penguin behaviour may have been altered by the transmitters.

\section{Travelling behaviour}

Although speed was not measured directly, the average rates of travel $\left(7.0 \pm 4.6 \mathrm{~km} \mathrm{~h}^{-1}\right)$ were comparable with those of $7.5 \mathrm{~km} \mathrm{~h}^{-1}$ measured in macaroni penguins (Brown 1987). No patterns in rates of travel were detected in this study, probably because many finescale foraging patterns cannot be discerned from satel- lite tracking data. Higher rates of travel on return legs of trips have been described previously in a number of penguin species (Williams \& Siegfried 1980, Croxall \& Lishman 1987, Kerry et al. 1995, Wilson et al. 1995, Bost et al. 1997). Increases in speed on both the outward and return trips to foraging grounds, compared to lower speeds in the feeding area, have also been described (Croxall \& Lishman 1987. Heath \& Randall 1989, Croxall \& Davis 1990).

The meandering coefficient indicated diurnal patterns, suggesting increased foraging activity from $07: 00$ to $18: 00 \mathrm{~h}$. This is consistent with diurnal foraging patterns described in previous studies of penguins (Williams \& Siegfried 1980, Wilson et al. 1989, Croxall et al. 1993, Bost et al. 1997, K. Green unpubl. data), and suggests that the meandering coefficient is a better indicator of foraging activity than rates of travel derived from satellite tracking data.

\section{Foraging zones and oceanographic influence}

The distances travelled during the incubation stage (over $600 \mathrm{~km}$ ) make royal penguins, along with king penguins (Jouventin et al. 1994), the most pelagic species of penguin studied to date. The data derived from this study also indicate: (1) that they are offshore feeders (Croxall \& Lishman 1987); (2) that foraging zones are not constant across the breeding season; and (3) that they travel further than previously assumed from extrapolations of studies at other localities (Horne 1985, Scott 1994)

All foraging was undertaken in a quadrant to the southeast of Macquarie Island, bounded by $54^{\circ} 30^{\prime}$ to $60^{\circ} \mathrm{S}$ and $158^{\circ} 54^{\prime}$ to $165^{\circ} \mathrm{E}$, indicating a non-random use of the ocean, as exhibited by other seabirds (Hunt et al. 1986, Baum 1987, Bost et al. 1997). The few observations of royal penguins at sea have not recorded them this far south or east (Woehler et al. 1990, Reid et al. in press), but this is probably a function of the lack of visits by ships to the eastern side of Macquarie Island. The penguins were foraging predominantly in water 4000 to $5000 \mathrm{~m}$ deep which accords with observations at sea (Reid et al. in press) and confirms the pelagic foraging habit of this species (Hindell 1988).

Foraging ranges tended to lie within the PFZ, predominantly near the northern boundary of the zone, probably in the sub-Antarctic Front (defined by water 5 to $9^{\circ} \mathrm{C}$; Burling 1961). The Antarctic Circumpolar Current (ACC) is a dominant feature of the PFZ, flowing in an easterly direction (Radok 1966, Gordon 1972). As the ACC approaches the Macquarie Ridge it is diverted southward and then loops north into the Emerald Basin, forcing relatively cooler water further north and causing mixing (Gordon 1972). Like most 
frontal zones, the PFZ is believed to restore nutrients in the region and enhance productivity (Ainley \& Jacobs 1981, Foster 1984, Abrams 1985, Lutjeharms et al. 1985, Schneider 1990). Seabirds have demonstrated associations with frontal zones (Haney \& McGillivary 1985) presumably due to the increases in productivity. This study shows that royal penguins, like king penguins around the Crozet Archipelago (Bost et al. 1997), exhibit an affinity with frontal zones.

Whilst myctophid fish and some cephalopods have a broad Antarctic/sub-Antarctic distribution, they are found closer to the surface and in higher concentrations in the PFZ (Hulley 1981, Gon \& Heemstra 1990). The diet of royal penguins 400 to $600 \mathrm{~km}$ from the colony is not known, but is assumed to be the same as that brought ashore, where it is dominated by euphausiids and myctophid fish, with some cephalopods taken (Hindell 1988). Presumably the PFZ near Macquarie Island exhibits high densities of prey, providing an abundant and/or predictable source of prey for these penguins.

Although average prey densities in the PFZ are purportedly higher and more predictable than other sectors of the Southern Ocean, prey are still regarded as patchy in distribution (Bost et al. 1997). CL within the foraging zones of royal penguins suggested a patchiness in prey distribution. Foraging patterns (meander coefficient and FZC) also suggested a difference in the availability of resources before and after the hatching of chicks. Foraging zones during the incubation period were circular with lower FZC compared to the guard stage. Circular tracks are thought to be related to unpredictable and patchy food resources in penguins (Jouventin et al. 1994, Wilson et al. 1995), and imply a 'systematic randomness' in foraging between patches as defined by Baum (1987) for other seabirds. After chicks hatched the tracks of the penguins were direct, with a higher FZC. This suggests more predictable resources in the sector, and a more systematic rather than random foraging behaviour (cf. Baum 1987), linked with the constraints of foraging trip durations during the breeding season due to the demands of chicks.

During the incubation stage, CL occurred generally throughout the foraging zone, whereas following the hatching of chicks it tended to be clumped (Fig. 7). However, CL did not correspond strongly to regions of increased standing stocks of phytoplankton. This discrepancy suggests that phytoplankton pigment concentrations may not be a good indicator of increased abundance of prey resources used by the penguins; or that the penguins did not forage in regions of the highest prey abundance.

Aside from guard stage and non-representative trips, overlap between foraging zones was generally low. The separate foraging zones used during different stages of the breeding season may represent either changes in the prey resources available in separate parts of the ocean during different times of year, or different food requirements of the penguins across the season (with different prey items being caught in different sectors of the ocean). Overriding any of these effects would be the activities at the nest which would constrain the duration of foraging trips.

Foraging trip duration, distance travelled and foraging area were all highly correlated, similar to the situation found in king penguins (Adams 1987). The duration of foraging trips was greatest during the incubation stage, which also concurs with other studies (Warham 1971, Carrick 1972, Croxall \& Prince 1980. Wilson et al. 1995). The major objective of foraging trips may also differ across the breeding season. The long foraging trips after an incubation shift, which involves a fast of up to $5 \mathrm{wk}$ in royal penguins (Carrick 1972, C. Hull unpubl. data), are probably required to restore body condition, whilst those carried out once chicks hatch may be predominantly to provide food for chicks. In contrast to the incubation stage, adults lose mass when foraging during chick rearing (Adams 1987. Brown 1987), suggesting a greater focus on acquiring food for chicks than on replenishing adult condition. This difference in the primary objectives between long and short trips may be comparable to the long and short foraging trips in procellariformes (Weimerskirch et al. 1994), although they are organised quite differently between the 2 groups of seabirds.

Royal penguins departing Macquarie Island followed a latitude of $54^{\circ} 33^{\prime} \mathrm{S}$ until $161^{\circ} \mathrm{E}$ longitude, with tracks in a clockwise direction. The consistent latitude used when departing the colony may indicate that the birds are taking advantage of the ACC, as has been proposed for other species (with other currents) (Randall et al. 1981). The ACC moves at a maximum speed of 15 to $20 \mathrm{~cm} \mathrm{~s}^{-1}$, and is very broad and deep, transporting water 2 to 3 times the rate of the Gulf Stream (Foster 1984). On return to Macquarie Island penguins may avoid the major flow of the current by approaching the island in a northwesterly direction.

\section{Conclusion}

This study has located the foraging grounds of royal penguins and demonstrated that they are much larger and more variable across the breeding season than has been assumed. Like king penguins (Jouventin et al. 1994), the foraging patterns of royal penguins appear to be intrinsically linked with the PFZ, and probably the availability of their prey. The changes in foraging patterns and behaviour of royal penguins are also strongly linked with the breeding biology of the species. 
Acknowledgements. We thank Jane Wilson, Kirsten Le Mar and Paul Scofield for assistance in the field, Al Rooke for downloading and relaying ARGOS data to us in the field, and Roger Hansworth and Dale Main for changing batteries on the devices. Funds were generously provided by the Charles A. and Anne Morrow Lindbergh Fund, the Japanese Penguin Fund, SeaWorld Research and Rescue Foundation, and the Antarctic Scientific Advisory Committee for various aspects of the work. The sea surface temperature and phytoplankton pigment concentration data were obtained from the NASA. Physical Ocnanography Distributed Active Archive Centre (PO.DAAC) at the Jet Propulsion Laboratory, California Institute of Technology, to whom we are grateful. Work was carried out under Macquarie Island special permits MI/3/95 and $\mathrm{MI} / 13 / 96$

\section{LITERATURE CITED}

Abrams RW (1985) Environmental determinants of pelagic seabird distribution in the African sector of the Southern Ocean. J Biogeogr 12:473-492

Abrams RW, Miller DGM (1986) The distribution of pelagic seabirds in relation to the oceanic environment of Gough Island. S Afr J Mar Sci 4:125-137

Adams NJ (1987) Foraging range of king penguins Aptenodytes patagonicus during summer at Marion Island J Zool Lond 212:475-482

Ainley DG, Jacobs SS (1981) Sea-bird affinities for ocean and ice boundaries in the Antarctic. Deep Sea Res 28: $1173-1185$

Ancel A, Kooyman GL, Ponganis PJ, Gendner JP, Lignon J, Mestre X, Huin N, Thornson PH, Robisson P, Le Maho Y (1992) Foraging behaviour of emperor penguin as a resource detector in winter and summer. Nature 360: $336-339$

Bannasch R, Wilson RP, Culik B (1994) Hydrodynamic aspects of design and attachment of a back-mounted device on penguins. J Exp Biol 194:83-96

Baum WM (1987) Random and systematic foraging, experimental studies of depletion, and schedules of reinforcement. In: Kamil AC, Krebs JR, Pulliam HR (eds) Foraging behaviour. Plenum Press, New York, p 587-607

Bost CA, Georges JY, Guinet C, Cherel Y, Pütz K, Charrassin JB, Handrich Y, Zorn T, Lage J, Le Maho Y (1997) Foraging habitat and food intake of satellite-tracked king penguins during the summer at Crozet Archipelago. Mar Ecol Prog Ser 150:21-33

Brown CR (1987) Travelling speed and foraging range of macaroni and rockhopper penguins at Marion Island. J Field Ornithol 58:118-125

Burling RW (1961) Hydrology of circumpolar waters south of New Zealand. NZ Oceanogr Inst Mem 10

Carrick R (1972) Population ecology of the Australian blackbacked magpie, royal penguin, and silver gull. Wildl Res Rep 2:41-99

Clarke BD, Bemis W (1979) Kinematics of swimming of penguins at Detroit Zoo. J Zool Lond 188:411-428

Copson GR, Rounsevell DE (1987) The abundance of royal penguins (eudyptes schlegeli Finsch) breeding at Macquarie Island. ANARE Res Note 41

Croxall JP, Briggs DR, Kato A, Naito Y, Watanuki Y, Williams TD (1993) Diving pattern and performance in the macaroni penguin Eudyptes chrysolophus. J Zool Lond 230: $31-47$

Croxall JP, Davis RW (1990) Metabolic rate and foraging behaviour of Pygoscelis and Eudyptes penguins at sea. In:
Davis LS, Darby JT (eds) Penguin biology. Academic Press, San Diego, p $207-228$

Croxall JP, Lishman GS (1987) The food and feeding ecology of penguins. In: Croxall JP (ed) Seabirds feeding ecology and role in marine ecosystems. Cambridge University Press, Cambridge, p 101-131

Croxall JP, Prince PA (1980) Food, feeding ecology and ecological segregation of seabirds at South Georgia. Biol J Linn Soc 4:103-131

Davis LS, Boersma PD, Court GS (1996) Satellite telemetry of the winter migration of Adélie penguins (Pygoscelis adeliae). Polar Biol 16:221 225

Ford G, Krumme DW (1979) 'The analysis of space use patterns. J Theor Biol 76:12, 10 j

Foster TD (1984) The marine environment. In: Laws RM (ed) Antarctuc ecology, Vol 2. Academic Press, London, p 345-371

Gon O, Heemstra PC (1990) Fishes of the Southern Ocean. JBL Smith Institute of Ichthyology, Grahamtown

Gordon AL (1972) On the interaction of the Antarctic Circumpolar Current and the Macquarie Ridge. In: Hayes DE (ed) Antarctic oceanology II. The Australian-New Zealand sector American Geophysical Union, National Academy of Sciences, New York, p 71-78

Haney JC (1986) Seabird affinities for Gulf Stream frontal eddies: responses of mobile marine consumers to episodic upwelling. J Mar Res 44:361-384

Haney JC, MCGillivary PA (1985) Midshelf fronts in the South Atlantic Bight and their influence on seabird distribution and seasonal abundance. Biol Ocean 3:401-430

Heath RGM, Randall RM (1989) Foraging ranges and movements of jackass penguins (Spheniscus demersus) eslablished through radio telemetry. J Zool Lond 217:367-379

Hindell MA (1988) The diet of the royal penguin Eudyptes schlegeli at Macquarie Island. Emu 88:219-226

Horne RSC (1985) Diet of royal and rockhopper penguins at Macquarie Island. Emu 85:150-156

Hull CL (in press a) Morphometric indices for sexing adult royal Eudyptes schlegeli and rockhopper E. chrysocome penguins at Macquarie Island. Mar Ornithol 24

Hull CL (in press b) The effect of carrying devices on breeding royal penguins. Condor

Hull CL, Wilson J (1996) The effect of investigators on the breeding success of royal Eudyptes schlegeli, and rockhopper penguins E. chrysocome at Macquarie Island. Polar Biol 16:335-337

Hulley PA (1981) Results of the research cruises of FRV 'Walter Herwig' to South America. LVIII. Family Myctophıdae (Osteichthys, Myctophimorphes). Arch FischWiss 31(1): $1-300$

Hunt GL (1988) The distribution of seabirds at sea: physical and biological aspects of thcir marine environment. Proc Int 100 DO-G Meeting. Curr Topics Avian Biol Bonn 167-171

Hunt GL (1990) The pelagic distribution of marine birds in a heterogeneous environment. Polar Res 8:43-54

Hunt GL, Eppley ZA, Schneider DS (1986) Reproductive performance of seabirds: the importance of population and colony size. Auk 103:306-317

Hunt GL, Schneider DC (1987) Scale-dependent processes in the physical and biological environment of marine birds. In: Croxall JP (ed) Seabirds: feeding ecology and role in marine ecosystems. Cambridge University Press, Cambridge, $\mathrm{p} 7-41$

Jouventin P, Capdeville D. Cuento-Chaillet F, Boiteau C (1994) Exploitation of pelagic resources by a non-flying seabirds: satellite tracking of the king penguin throughout the breeding cycle. Mar Ecol Prog Ser 106:11-19 
Kerry KR, Clarke JR, Else GD (1995) The foraging range of Adélie penguins at Berhervaise Island, MacRobertson Land. Antarctic as determined by satellite telemetry. In: Dann P. Norman I, Reilly P (eds) The penguins: ecology and management. Surrey Beatty and Sons, Melbourne, p 216-243

Lutjeharms JRE, Walters NM, Allanson BR (1985) Oceanic frontal systems and biological enhancement. In: Siegfried WR, Condy PR, Laws RN (eds) Antarctic nutrient cycles and food webs. Springer-Verlag, Berlin, p 11-21

McConnell BJ, Chambers C, Fedak MA (1992) Foraging ecology of southern elephant seals in relation to the bathometry and productivity of the Southern Ocean. Antarct Sci 4 393-398

Radok R (1966) Ocean surface waves and swell. In: Symposium on Antarctic Oceanography, SCAR. Heffer and Sons, Cambridge, p 30-33

Randall RM, Randall BM, Baird D (1981) Speed and movement of jackass penguins and their possible use of ocean currents. S Afr J Sci 77:420-421

Reid TA, Hull CL, Woehler EJ (in press) Shipboard observations of penguins at sea, 1991-1995. Proc 3rd Int Penguin Conf Mar Ornithol

Schneider DC (1990) Seahirds and fronts a brief overyiew Polar Res 8:17-21

Scott J (1994) Marine conservation at Macquarie Island. A marine conservation strategy and an account of the marine environment. Tasmania: Parks and Wildlife Service and Ocean Rescue 2000, Hobart

Stewart BS, DeLong RL (1995) Double migrations of the northern elephant seal Mirounga angustirostris. J Mammal 76:196-205

Stewart BS, Leatherwood S, Yochim PK, Heide-Jørgensen MP (1989) Harbor seal tracking and telemetry by satellite. Mar Mamm Sci 5:361-375

Veit RR, Silverman ED, Everson I (1993) Aggregation patterns of pelagic predators and their principle prey, Antarctic krill, near South Georgia. J Anim Ecol 62:551-564

This article was submitted to the editor
Walker K. Elliott G, Nicholls D, Murray D, Dilks P (1995) Satellite tracking of wandering albatross (Diomedea exulansj from the Auckland Islands: preliminary results. Notornis 42:127-137

Warham J (1971) Aspects of breeding behaviour in the royal penguin Eudyptes chrysolophus schlegeli. Notornis 18: $91-115$

Weavers BW (1992) Seasonal foraging ranges and travels at sea of little penguins Eudyptula minor, determined by radiotracking. Emu 91:302-317

Weimerskirch $H$, Chastel $O$, Ackermann $L$, Chaurand $T$, Cuenot-Chaillet F, Hindermeyer X, Judas J (1994) Alternative long and short foraging trips in pelagic seabird parents. Anim Behav 47:472-476

White LC, Garrott RA (1990) Analysis of wildlife radiotracking data. Academic Press, San Diego

Williams AJ, Siegfried WR (1980) Foraging ranges of krilleating penguins. Polar Rec 125:159-162

Wilson RP, Grant WS, Duffy DC (1986) Recording devices on free-ranging marine animals: does measurement affect performance? Ecology 67:1091-1093

Wilson RP, Nagy KA, Obst BS (1989) Foraging ranges of penguins. Polar Rec 25:303 30 ?

Wilson RP, Scolaro JA, Peters G, Laurenti S, Kierspel M, Gallelli H, Upton J (1995) Foraging areas of Magellanic penguins Spheniscus magellanicus breeding at San Lorenzo, Argentina, during the incubation period. Mar Ecol Prog Ser 129:1-6

Woehler EJ, Hodges CL, Watts DJ (1990) An atlas of the pelagic distribution of seabirds in the southern Indian Ocean, 1981 to 1990. ANARE Res Notes 77

Wray S, Cresswell WJ, White PCL, Harris S (1992) What, if anything, is a core area? An analysis of the problems of describing internal range configurations. In: Priede IM, Swift SM (eds) Wildlife telemetry. Remote monitoring and tracking of animals. Ellis Horwood, London, p $256-271$

Manuscript first received: January 10,1997

Revised version accepted: April 28, 1997 